\title{
UI MUTU FISIK DAN AKTIVITAS ANTIOKSIDAN FORMULA KRIM KOMBINASI EKSTRAK ETANOL GANGGANG HIJAU (Ulva latuca L.) DAN LIDAH BUAYA (Aloe vera) SEBAGAI PERAWATAN KULIT WAJAH
}

\author{
Wening Hanifah ${ }^{1}$, Emelda $^{2 *}$, Veriani Aprilia ${ }^{3}$, Annisa Fatmawati ${ }^{4}$
}

\author{
1Program Studi S1 Farmasi Fakultas IImu-IImu Kesehatan Universitas Alma Ata \\ ${ }^{2}$ Program Studi S1 Farmasi Fakultas Ilmu-Ilmu Kesehatan Universitas Alma Ata \\ ${ }^{3}$ Program Studi S1 Gizi Fakultas Ilmu-Ilmu Kesehatan Universitas Alma Ata \\ ${ }^{4}$ Program Studi S1 Farmasi Fakultas Ilmu-Ilmu Kesehatan Universitas Alma Ata \\ Email: weninghanifah@gmail.com,emelda@almaata.ac.id, aprilia.triwanto@gmail.com, \\ annisafatmauaa2019@gmail.com \\ Korespondensi: \\ Emelda \\ Program Studi S1 Farmasi Fakultas IImu-IImu Kesehatan Universitas Alma Ata \\ emelda@almaata.ac.id
}

\begin{abstract}
Abstrak
Antioksidan merupakan molekul yang dapat memperlambat atau mencegah proses terjadinya oksidasi. Oksidasi merupakan reaksi kimia yang dapat menghasilkan radikal bebas. Paparan radikal bebas seperti sinar matahari, polusi udara, obat-obatan, asap rokok secara terus menerus akan menyebabkan kulit tampak kering, kusam, lesi kulit, dan juga penuaan dini. Ganggang hijau (Ulva Lactuca L.) dan lidah buaya (Aloe Vera) telah diteliti memiliki aktivitas antioksidan, sehingga tujuan dari penelitian ini adalah untuk mengetahui formula terbaik berdasarkan mutu fisik dan aktivitas antioksidan krim kombinasi ekstrak etanol ganggang hijau (EEGH) dan lidah buaya (EELB) dengan metode DPPH. Jenis penelitian yang digunakan adalah eksperimental laboratorium terhadap 5 formula sediaan krim dengan perbedaan jumlah ekstrak serta dilakukan uji mutu fisik dan aktivitas antioksidan sediaan krim pada hari ke-0 menggunakan spektrofotometer UV-Vis. Krim formula 1 memiliki daya sebar, daya lekat dan aktivitas antioksidan sebesar $4,5 \mathrm{~cm}, 10,456$ detik, IC ${ }_{50} 802,038 \mu \mathrm{g} / \mathrm{mL}$. Formula 2 sebesar $3,1 \mathrm{~cm}, 4,59$ detik, $I_{50} 1.643,955 \mu \mathrm{g} / \mathrm{mL}$. Formula 3 sebesar 4,833 cm, 13,993 detik, IC $\mathrm{C}_{50} 304,41 \mu \mathrm{g} / \mathrm{mL}$. Formula 4 sebesar $3,766 \mathrm{~cm}, 9,806$ detik, $\mathrm{IC}_{50} 559,453 \mu \mathrm{g} /$ $\mathrm{mL}$. Formula 5 sebesar $3,833 \mathrm{~cm}, 9,116$ detik, $\mathrm{IC}_{50} 2.227 \mu \mathrm{g} / \mathrm{mL}$. Hasil penelitian menunjukkan bahwa formula 3 merupakan formula terbaik berdasarkan uji mutu fisiknya dengan nilai daya sebar sebesar 4,833 cm, daya lekat 13,993 detik, dan aktivitas antioksian ditunjukkan dengan nilai IC ${ }_{50}$ sebesar $304,411 \mu \mathrm{g} / \mathrm{mL}$.
\end{abstract}

Kata Kunci: antioksidan; ganggang hijau; lidah buaya

\section{PHYSICAL QUALIT Y TEST AND ANTIOXIDANT ACTIVITIES OF CREAM FORMULA COMBINATION OF GREEN GANGGANG ETHANOL EXTRACT (Ulva latuca L.) AND VERA VERA (Aloe vera) AS A FACIAL SKIN TREATMENT}

\begin{abstract}
Antioxidants are molecules that can slow down or prevent the oxidation process from occurring. Oxidation is a chemical reaction that can produce free radicals. Continuous exposure to free radicals such as sunlight, air pollution, drugs, cigarette smoke will cause skin to look dry, dull, skin lesions, and also premature aging. Green algae (Ulva lactuca L.
\end{abstract}


and Aloe Vera (Aloe vera) have been studied to have antioxidant activity, so the aim of this study was to determine the best formula based on physical quality and antioxidant activity of the combination cream of green algae (EEGH) ethanol extract and aloe vera (EELB) using the DPPH method. This type of research is a laboratory experimental study of 5 formulas for cream preparations with different amounts of extracts. Physical quality tests and antioxidant activity of cream preparations were carried out on day 0 using a UV-Vis spectrophotometer. Cream offormula 1 has the dispersibility, adhesion and antioxidant activity of $4.5 \mathrm{~cm}, 10.456$ seconds, $I C_{50} 802,038 \mu \mathrm{g} / \mathrm{mL}$. Formula 2 is $3.1 \mathrm{~cm}$, 4.59 seconds, $I C_{50} 1.643,955 \mu \mathrm{g} / \mathrm{mL}$. Formula 3 is 4,833 cm, 13,993 seconds, $I C_{50} 304,411 \mu \mathrm{g} / \mathrm{mL}$. Formula 4 is 3,766 cm, 9.806 seconds, $I C_{50} 559,453 \mu \mathrm{g} / \mathrm{mL}$. Formula 5 is $3,833 \mathrm{~cm}, 9,116$ seconds, $I C_{50} 2.227 \mu \mathrm{g} / \mathrm{mL}$. The results showed that formula 3 was the best formula based on its physical muti test with a spreadability value of $4.833 \mathrm{~cm}$, adhesion of 13.993 seconds, and anti-oxidation activity indicated by an $1 C_{50}$ value of $304,411 \mu \mathrm{g} / \mathrm{mL}$.

Keywords: aloe vera; antioxidants; green algae

\section{PENDAHULUAN}

Antioksidan merupakan molekul yang dapat memperlambat atau mencegah proses terjadinya oksidasi ${ }^{1}$. Oksidasi merupakan reaksi kimia yang dapat menghasilkan radikal bebas. Paparan radikal bebas seperti sinar matahari, polusi udara, obat-obatan, asap rokok secara terus menerus akan menyebabkan kulit tampak kering, kusam, lesi kulit, dan juga penuaan dini ${ }^{2,3}$. Upaya yang dapat dilakukan untuk mendapatkan kulit wajah yang bagus dengan hasil yang cepat yaitu dengan melakukan perawatan wajah menggunakan kosmetik yang banyak beredar dipasaran. Namun demikian, kosmetik yang beredar di pasaran saat ini masih banyak ditemui sediaan yang mengandung bahan kimia berbahaya yang dapat merusak kulit dan hal ini tidak disadari oleh masyarakat.

Senyawa fenol, flavonoid serta senyawa karoten secara umum terkandung pada rumput laut hijau (Ulva lactuca L.) berfungsi sebagai antioksidan ${ }^{4}$. Ganggang hijau merupakan salah satu contoh rumput laut (alga) memiliki senyawa phytomelatonin yang merupakan zat aktif dari melatonin sebagai aktivitas antioksidan kuat yang dapat menangkal radikal bebas ${ }^{5}$. Ekstrak etanol ganggang hijau (Ulva lactuca) yang berasal dari Pantai Sepanjang Gunung Kidul memiliki kemampuan menghambat radikal bebas lebih baik dari pada asam askorbat dengan nilai IC50 masing-masing $17,25 \mu \mathrm{g} / \mathrm{ml}$ dan $28,9 \mu \mathrm{g} / \mathrm{mL}^{6}$, begitu juga ekstrak etanol ganggang hijau memiliki kemampuan menghambat radikal bebas lebih rendah dari pada asam galat dengan ditunjukkan nilai $\mathrm{IC}_{50}$ masing-masing sebesar $21,34 \mu \mathrm{g} / \mathrm{mL}$ dan $2,76 \mu \mathrm{g} / \mathrm{mL}^{7}$.

Lidah buaya (Aloe vera) bersifat fungsional karena dapat dimanfaatkan untuk mengobati penyakit maupun perawatan tubuh ${ }^{8}$. Kandungan flavonoid yang terkandung 
Wening Hanifah, Emelda, Veriani Aprilia, Annisa Fatmawati

Uji Mutu Fisik dan Aktivitas Antioksidan Formula Krim Kombinasi Ekstrak Etanol Ganggang Hijau

(Ulva Latuca L.) dan Lidah Buaya (Aloe Vera) Sebagai Perawatan Kulit Wajah

didalam ekstrak etanol lidah buaya dapat memberikan aktivitas sebagai antioksidan dengan nilai IC ${ }_{50} 58,36 \mu \mathrm{g} / \mathrm{mL}^{9}$, begitu juga ekstrak lidah buaya memiliki kemampuan menghambat radikal bebas lebih rendah dari pada asam galat dengan ditunjukkan nilai $\mathrm{IC}_{50}$ masing-masing sebesar $64,81 \mu \mathrm{g} / \mathrm{mL}$ dan $2,76 \mu \mathrm{g} / \mathrm{mL}^{7}$.

Ganggang hijau mengandung senyawa antioksidan sedangkan lidah buaya juga mengandung flavonoid sebagai antioksidan dan vitamn $\mathrm{C}$ yang dapat berfungsi sebagai pelembab dan pencerah kulit sehingga harapannya kedua bahan alam ini apabila dikombinasikan dan dibuat dalam sediaan krim dapat berfungsi sebagai perawatan kulit wajah secara alami. Formula krim kombinasi tersebut kemudian di uji mutu fisik dan aktivitas antioksidannya dengan metode DPPH.

\section{METODE PENELITIAN}

\section{Alat dan Bahan}

Jenis penelitian yang dilakukan adalah penelitian eksperimental laboratorium dengan membuat 5 formula krim dengan dilakukan uji mutu fisik dan aktivitas antioksidannya. Alat yang digunakan pada penelitian ini diantaranya adalah bejana maserasi, alat-alat gelas laboratorium, tabung reaksi, aluminium foil, blender, neraca analitik, kompor listrik, evaporator, waterbath, mortar dan stamper, batang pengaduk, cawan porselin, corong pisah, kertas saring, $\mathrm{pH}$ universal, kaca untuk uji daya lekat dan daya sebar beserta bebannya, kuvet, spektrofotometer UV-Vis. Bahan yang digunakan pada penelitian ini diantaranya adalah ganggang hijau, lidah buaya, etanol 96\%, metanol, asam galat, senyawa DPPH, setil alkohol, gliserin, TEA, asam stearat, metil paraben, propil paraben, VCO, aquades dan reagen untuk uji pendahuluan.

\section{Rancangan Penelitian}

Penelitian ini akan dilaksanakan di Laboratorium Teknologi Farmasi Fakultas IImuIImu Kesehatan Universitas Alma Ata Yogyakarta dari bulan Januari sampai Agustus 2020. Sampel pada penelitian ini adalah ganggang hijau jenis Ulva lactuca $L$. yang diambil dari Pantai Sepanjang Gunung Kidul Yogyakarta dan lidah buaya (Aloe vera) yang diambil dari Desa Gebangsari Tambak Banyumas.

Data yang diambil merupakan data kualitatif yang meliputi organoleptis dan homogenitas. Sedangkan, data kuantitatif meliputi pH, daya sebar, daya lekat dan aktivitas antioksidan pada sediaan krim. Pengumpulan data akan dilakukan pada hari ke- 0 . Analisis data menggunakan pendekatan statistik dengan one sample Shapiro Wilk, terdistribusi normal, maka dilanjutkan dengan Analisa one-way Anova pada taraf kepercayaan 95\%, diteruskan 
dengan uji post hoc pada setiap percobaan karena terdapat perbedaan yang signifikan.

\section{Pembuatan Ekstrak Ganggang Hijau dan Lidah Buaya}

Pembuatan ekstrak ganggang hijau dengan cara maserasi, sebanyak 500gram sampel yang sudah dikeringkan dibawah sinar matahari dan diblender kemudian dimasukkan dalam pelarut etanol 96\% sebanyak $2 \mathrm{~L}$ sesekali diaduk, maserasi diulangi 2 kali. Maserat yang didapatkan kemudian disaring dan diuapkan dengan evaporator pada suhu $40^{\circ} \mathrm{C}$ sampai terbentuk ekstrak kental sebanyak 40,06 gram.

Pembuatan ekstrak lidah buaya dengan cara maserasi, sebanyak 839gram dimasukkan kedalam pelarut etanol $96 \%$ sebanyak $2 \mathrm{~L}$, maserasi diulangi 2 kali. Maserat yang didapatkan kemudian disaring dan diuapkan dengan evaporator pada suhu $37^{\circ} \mathrm{C}$ sampai terbentuk ekstrak kental sebanyak 10,06gram.

\section{Pembuatan Formula Krim}

Cara pembuatan krim: krim tipe oil in water $(\mathrm{O} / \mathrm{W})$ dibuat dengan cara menambahkan fase water (aquades, TEA, metil paraben) yang sudah dipanaskan diatas tangas air suhu $70^{\circ} \mathrm{C}$ kedalam fase oil (asam stearat, setil alkohol, gliserin, propil paraben, VCO) yang juga sudah dipanaskan di penangas air suhu $70^{\circ} \mathrm{C}$ kemudian dengan dilakukan pengadukan yang konstan menggunakan mortar sampai terbentuk basis krim kemudian ditambahkan ekstrak ganggang hijau dan lidah buaya kedalam basis krim yang telah terbentuk (Tabel 1).

Tabel I. Formula Krim Ganggang Hijau dan Lidah Buaya

\begin{tabular}{cccccc}
\hline \multirow{2}{*}{ Bahan } & \multicolumn{5}{c}{ Bobot (g) } \\
\cline { 2 - 6 } & F1 & F2 & F3 & F4 & F5 \\
\hline EEGH & $2 \mathrm{~g}$ & - & $1,5 \mathrm{~g}$ & $1 \mathrm{~g}$ & $0,5 \mathrm{~g}$ \\
EELB & - & $2 \mathrm{~g}$ & $0,5 \mathrm{~g}$ & $1 \mathrm{~g}$ & $1,5 \mathrm{~g}$ \\
Setil alkohol & $1 \mathrm{~g}$ & $1 \mathrm{~g}$ & $1 \mathrm{~g}$ & $1 \mathrm{~g}$ & $1 \mathrm{~g}$ \\
Gliserin & $3,75 \mathrm{~g}$ & $3,75 \mathrm{~g}$ & $3,75 \mathrm{~g}$ & $3,75 \mathrm{~g}$ & $3,75 \mathrm{~g}$ \\
TEA & $0,75 \mathrm{~g}$ & $0,75 \mathrm{~g}$ & $0,75 \mathrm{~g}$ & $0,75 \mathrm{~g}$ & $0,75 \mathrm{~g}$ \\
Asam stearate & $3 \mathrm{~g}$ & $3 \mathrm{~g}$ & $3 \mathrm{~g}$ & $3 \mathrm{~g}$ & $3 \mathrm{~g}$ \\
Metil paraben & $0,05 \mathrm{~g}$ & $0,05 \mathrm{~g}$ & $0,05 \mathrm{~g}$ & $0,05 \mathrm{~g}$ & $0,05 \mathrm{~g}$ \\
Propil paraben & $0,005 \mathrm{~g}$ & $0,005 \mathrm{~g}$ & $0,005 \mathrm{~g}$ & $0,005 \mathrm{~g}$ & $0,005 \mathrm{~g}$ \\
VCO & $2,5 \mathrm{~g}$ & $2,5 \mathrm{~g}$ & $2,5 \mathrm{~g}$ & $2,5 \mathrm{~g}$ & $2,5 \mathrm{~g}$ \\
Aquades & 11,945 & 11,945 & 11,945 & 11,945 & 11,945 \\
Total & $25 \mathrm{~g}$ & $25 \mathrm{~g}$ & $25 \mathrm{~g}$ & $25 \mathrm{~g}$ & $25 \mathrm{~g}$ \\
\hline
\end{tabular}

Keterangan: EEGH: Ekstrak Etanol Ganggang Hijau; EELB: Ekstrak Etanol Lidah Buaya; F1 Formula 1 (penambahan ekstrak etanol ganggang hijau 2 gram); F2: Formula 2 (penambahan ekstrak etanol lidah buaya sebanyak 2 gram); F3: Formula 3 (penambahan ekstrak ganggang 
Wening Hanifah, Emelda, Veriani Aprilia, Annisa Fatmawati

Uji Mutu Fisik dan Aktivitas Antioksidan Formula Krim Kombinasi Ekstrak Etanol Ganggang Hijau (Ulva Latuca L.) dan Lidah Buaya (Aloe Vera) Sebagai Perawatan Kulit Wajah

hijau dan lidah buaya masing-masing 1,5gram dan 0,5 gram); F4: Formula 4 (penambahan ekstrak ganggang hijau dan lidah buaya masing-masing 1 gram); F5: Formula 5 (penambahan ekstrak ganggang hijau dan lidah buaya masing-masing 0,5gram dan 1,5 gram)

\section{HASIL DAN PEMBAHASAN}

\section{Rendemen Ekstrak Ganggang Hijau dan Lidah Buaya}

Hasil rendemen ekstrak kental ganggang hijau didapatkan sebesar 8,012\%, sedangkan hasil rendemen ekstrak kental lidah buaya sebesar 1,20\%.

\section{Uji Mutu Fisik Krim}

Uji organoleptis sediaan krim meliputi warna, bentuk, bau secara visual (Tabel 2). Selain itu, telah dilakukan pula uji homogenitas sediaan krim yang dilakukan secara visual. Tujuannya adalah melihat apakah sediaan tersebut homogen atau tidak dengan dioleskan sediaan pada kaca arloji dan dilihat apakah terdapat gumpalan atau warna yang tidak merata dan jika perlu dilakukan sentuhan menggunakan tangan ${ }^{10}$.

Tabel II. Uji Organoleptis Sediaan Krim

\begin{tabular}{clll}
\hline Formula & \multicolumn{1}{c}{ Warna } & \multicolumn{1}{c}{ Bau } & \multicolumn{1}{c}{ Bentuk } \\
\hline 1 & Hijau & Bau khas ganggang hijau & Konsistensi kental, padat \\
2 & Coklat & Bau khas lidah buaya & Konsistensi kental, sedikit lembek \\
3 & Hijau & Tidak berbau & Konsistensi kental, padat \\
4 & Hijau pucat & Tidak berbau & Konssistensi kental padat \\
5 & Coklat & Tidak berbau & Konsistensi kental, sedikit lembek \\
& kehijauan & & \\
\hline
\end{tabular}

Hasil uji homogenitas krim dapat dilihat pada Tabel 3 yang menunjukkan bahwa kelima formula sediaan krim adalah homogen.

Tabel III. Uji Homogenitas Sediaan Krim

\begin{tabular}{cl}
\hline Formula & Homogenitas \\
\hline 1 & Homogen \\
2 & Homogen \\
3 & Homogen \\
4 & Homogen \\
5 & Homogen \\
\hline
\end{tabular}

Uji pH pada sediaan krim dilakukan untuk memastikan bahwa pH sedian krim dapat diterima oleh $\mathrm{pH}$ kulit, dilakukan dengan cara 5 gram sampel krim dilarutkan aquades 45 $\mathrm{mL}$ kemudian dicek dengan stik $\mathrm{pH}$ universal. $\mathrm{pH}$ sediaan yang baik antara 4,5-6,5 dan pH kulit 4,5-7, $5^{11}$. Hasil uji pH pada kelima formula krim dapat dilihat pada Tabel 4 yaitu sebesar 
7 artinya tidak menunjukkan perbedaan dari kelima formula krim dan dapat diterima oleh pH kulit sehingga kelima formula sediaan krim dapat digunakan dan tidak mengiritasi kulit.

Tabel IV. Uji pH Sediaan Krim

\begin{tabular}{cc}
\hline Formula & pH \\
\hline 1 & 7 \\
2 & 7 \\
3 & 7 \\
4 & 7 \\
5 & 7 \\
\hline
\end{tabular}

Uji daya sebar pada sediaan krim dilakukan untuk mengetahui luas penyebaran sediaan krim apabila sudah diaplikasikan pada kulit, yaitu dengan cara mengoleskan 1 gram krim diatas kaca bundar kemudian ditutup dengan kaca lainnya, biarkan 1 menit ukur diameternya. Tahap selanjutnya tambahkan beban 50gram biarkan 1 menit dan diukur diameternya. Daya sebar sediaan topikal yang baik antara $5-7 \mathrm{~cm}^{12,11}$. Semakin luas permukaan membran tempat sediaan krim menyebar maka koefisien difusinya akan semakin besar, sehingga difusi obat semakin meningkat. Semakin besar daya sebar sediaan krim maka akan semakin baik ${ }^{13}$. Hasil uji daya sebar krim dapat dilihat pada Tabel 5 maka formula yang memiliki daya sebar paling baik adalah formula 3 sebesar 4,833 cm, meskipun krim tidak memenuhi syarat akan tetapi memiliki nilai daya sebar yang mendekati range syarat daya sebar yang baik pada sediaan topikal.

Tabel V. Uji Daya Sebar Sediaan Krim

\begin{tabular}{ccc}
\hline Formula & $\begin{array}{c}\text { Daya sebar } \\
(\mathbf{c m})\end{array}$ & $\begin{array}{c}\text { Rata-rata daya sebar } \\
(\mathbf{c m})\end{array}$ \\
\hline & 4 & \\
& 4,5 & 4,5 \\
& 5 & \\
2 & 2,7 & 3,1 \\
& 3 & \\
& 3,6 & \\
3 & 3,5 & 4,833 \\
& 4,5 & \\
4 & 6,5 & 3,766 \\
& 3,5 & \\
& 3,8 & \\
5 & 4 & 3,833 \\
& 3,7 & \\
\hline
\end{tabular}


Uji daya lekat pada sediaan krim dilakukan untuk mengetahui lamanya sediaan krim melekat pada kulit yaitu dengan cara mengoleskan 1 gram krim diatas plat kaca bundar, tambahkan beban $1 \mathrm{~kg}$ selama 5 menit kemudian dilepaskan, tahap pengujian selanjutnya ditambahkan beban pelepas seberat 80 gram dan dicatat waktu kedua plat terlepas. Daya lekat sediaan topikal yang baik adalah lebih dari 4 detik, semakin lama waktu diperoleh maka kemampuan krim untuk dapat melekat pada kulit semakin bagus ${ }^{12,11}$. Hasil uji daya lekat yang paling baik adalah formula 3 yaitu sebesar 13,993 detik dapat dilihat pada Tabel 6 .

Tabel VI. Uji Daya Lekat Sediaan Krim

\begin{tabular}{ccc}
\hline Formula & Daya lekat (detik) & Rata-rata daya lekat (detik) \\
\hline \multirow{2}{*}{1} & 2,6 & \\
& 10.13 & 10,456 \\
& 18,64 & \\
2 & 4,29 & 4,59 \\
& 4,60 & \\
& 4,88 & 13,993 \\
3 & 9,82 & \\
& 11,82 & \\
& 20,34 & 9,806 \\
4 & 7,72 & \\
& 9,76 & \\
& 11,94 & 9,116 \\
5 & 8,38 & \\
& 8,82 & \\
\end{tabular}

\section{Uji Aktivitas Antioksidan Sediaan Krim}

Pembuatan larutan blangko dilakukan dalam penelitian ini dengan menggunakan larutan DPPH 0,5 mM sebanyak $2 \mathrm{~mL}$ yang dimasukkan ke tabung reaksi dengan ditambah $2 \mathrm{~mL}$ metanol, gojok hingga homogen dan dibaca absorbansinya pada panjang gelombang $400-800 \mathrm{~nm}^{14}$. Hasil pengukuran panjang gelombang maksimal DPPH yaitu sebesar $517 \mathrm{~nm}$. Pengukuran aktivitas antioksidan dengan metode DPPH dilakukan juga dengan pembutan larutan asam galat (kontrol positif) yaitu dengan cara menimbang asam galat sebanyak 10 mg dilarutkan dengan metanol hingga $100 \mathrm{ml}(100 \mu \mathrm{g} / \mathrm{mL})$ sebagai larutan induk. Kemudian dari larutan induk dibuat larutan seri konsentrasi 1,4; 1,8;2,2; 2,6; $3 \mu \mathrm{g} / \mathrm{mL}$ dan ditambah metanol hingga $10 \mathrm{~mL}$. Masing-masing larutan uji daimbil $2 \mathrm{~mL}$ dan ditambah $2 \mathrm{~mL}$ DPPH 0,5 mM, gojok dan diinkubasi pada suhu kamar selama 30 menit dan baca absorbansinya pada lamda $517 \mathrm{~nm}^{15}$. Hasil aktivitas antioksidan pada asam galat dapat dilihat pada Tabel 7 yang menunjukkan bahwa nilai $\mathrm{IC}_{50}$ dari asam galat sebesar $4,496 \mu \mathrm{g} / \mathrm{mL}$ tergolong sangat 
kuat karena nilai $\mathrm{IC}_{50}$ kurang dari $50 \mu \mathrm{g} / \mathrm{mL}$.

Tabel VII. Aktivitas Antioksidan Asam Galat

\begin{tabular}{cccc}
\hline Konsentrasi & Absorbansi & \% inhibisi & IC $_{50}$ \\
\hline $1,4 \mu \mathrm{g} / \mathrm{mL}$ & 0,494 & 55,45 & \\
$1,8 \mu \mathrm{g} / \mathrm{mL}$ & 0,501 & 54,82 & \\
$2,2 \mu \mathrm{g} / \mathrm{mL}$ & 0,516 & 53,47 & $4,496 \mu \mathrm{g} / \mathrm{mL}$ \\
$2,6 \mu \mathrm{g} / \mathrm{mL}$ & 0,514 & 53,65 & \\
$3 \mu \mathrm{g} / \mathrm{mL}$ & 0,526 & 52,56 & \\
\hline
\end{tabular}

Hasil pengukuran aktivitas antioksidan pada sampel krim yang dilakukan dengan cara menimbang 2,5 gram krim dilarutkan kedalam metanol $50 \mathrm{~mL}(1000 \mu \mathrm{g} / \mathrm{mL})$ sebagai larutan induk, kemudian dibuat seri konsentrasi 10;20;30;40;50 $\mu \mathrm{g} / \mathrm{mL}$ dan ditambah metanol hingga $10 \mathrm{~mL}$, dari beberapa seri konsentrasi tersebut kemudian diambil $2 \mathrm{~mL}$ dan ditambahkan $2 \mathrm{~mL}$ DPPH 0,5mM, selanjutnya didiamkan selama 30 menit pada suhu ruang dan dibaca absorbansinya pada lamda $517 \mathrm{~nm}(14,16)$. Hasil aktivitas antioksian pada sediaan krim dapat dilihat pada Tabel 8 yang menunjukkan bahwa nilai I $C_{50}$ pada formula 1 adalah $802,038 \mu \mathrm{g} / \mathrm{mL}$ tergolong sangat lemah karena nilai IC ${ }_{50}$ lebih dari $500 \mu \mathrm{g} / \mathrm{mL}$. Nilai IC 50 pada formula 2 adalah 1.643,955 $\mu \mathrm{g} / \mathrm{mL}$ tergolong sangat lemah karena nilai IC $\mathrm{I}_{50}$ lebih dari 500 $\mu \mathrm{g} / \mathrm{mL}$. Nilai $\mathrm{IC}_{50}$ formula 3 adalah 304,411 $\mu \mathrm{g} / \mathrm{mL}$ tergolong lemah karena nilai IC ${ }_{50}$ diantara range $250-500 \mu \mathrm{g} / \mathrm{mL}$. Nilai $\mathrm{IC}_{50}$ formula 4 adalah $559,453 \mu \mathrm{g} / \mathrm{mL}$ tergolong sangat lemah

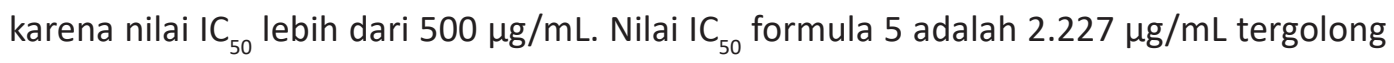
sangat lemah karena nilai IC $C_{50}$ lebih dari $500 \mu \mathrm{g} / \mathrm{mL}$. Pada penelitian sebelumnya, nilai $\mathrm{IC}_{50}$ ekstrak ganggang hijau sebesar $21,34 \mu \mathrm{g} / \mathrm{mL}$ tergolong sangat kuat karena nilai $\mathrm{IC}_{50}$ kurang dari $50 \mu \mathrm{g} / \mathrm{mL}$ dan nilai IC ${ }_{50}$ ekstrak lidah buaya sebesar $64,81 \mu \mathrm{g} / \mathrm{mL}$ tergolong kuat karena nilai IC ${ }_{50}$ kurang dari $100 \mu \mathrm{g} / \mathrm{mL}^{7}$.

Tabel VIII. Aktivitas Antioksidan Sediaan Krim

\begin{tabular}{cccc}
\hline Formula & konsentrasi & \% inhibisi & IC $_{50}(\mu \mathrm{g} / \mathrm{mL})$ \\
\hline & $10 \mu \mathrm{g} / \mathrm{mL}$ & 12,623 & \\
& $20 \mu \mathrm{g} / \mathrm{mL}$ & $-0,540$ & \\
1 & $30 \mu \mathrm{g} / \mathrm{mL}$ & 9,257 & 802,038 \\
& $40 \mu \mathrm{g} / \mathrm{mL}$ & 7,183 & \\
& $50 \mu \mathrm{g} / \mathrm{mL}$ & 11,481 & \\
$10 \mu \mathrm{g} / \mathrm{mL}$ & 10,970 & \\
& $20 \mu \mathrm{g} / \mathrm{mL}$ & $-3,426$ & \\
& $30 \mu \mathrm{g} / \mathrm{mL}$ & 5,770 & $1.643,955$ \\
2 & $40 \mu \mathrm{g} / \mathrm{mL}$ & 8,926 & \\
& $50 \mu \mathrm{g} / \mathrm{mL}$ & 3,456 & \\
& $10 \mu \mathrm{g} / \mathrm{mL}$ & 37,390 &
\end{tabular}


Wening Hanifah, Emelda, Veriani Aprilia, Annisa Fatmawati

Uji Mutu Fisik dan Aktivitas Antioksidan Formula Krim Kombinasi Ekstrak Etanol Ganggang Hijau (Ulva Latuca L.) dan Lidah Buaya (Aloe Vera) Sebagai Perawatan Kulit Wajah

\begin{tabular}{cccc}
\hline Formula & konsentrasi & \% inhibisi & $\mathbf{I C}_{50}(\mu \mathrm{g} / \mathrm{mL})$ \\
\hline \multirow{3}{*}{3} & $20 \mu \mathrm{g} / \mathrm{mL}$ & 37,420 & \\
& $30 \mu \mathrm{g} / \mathrm{mL}$ & 38,382 & 304,411 \\
& $40 \mu \mathrm{g} / \mathrm{mL}$ & 38,262 & \\
& $50 \mu \mathrm{g} / \mathrm{mL}$ & 39,013 & \\
& $10 \mu \mathrm{g} / \mathrm{mL}$ & 41,208 & \\
& $20 \mu \mathrm{g} / \mathrm{mL}$ & 38,743 & \\
4 & $30 \mu \mathrm{g} / \mathrm{mL}$ & 39,194 & 559,453 \\
& $40 \mu \mathrm{g} / \mathrm{mL}$ & 41,478 & \\
& $50 \mu \mathrm{g} / \mathrm{mL}$ & 40,847 & \\
& $10 \mu \mathrm{g} / \mathrm{mL}$ & 37,390 & \\
& $20 \mu \mathrm{g} / \mathrm{mL}$ & 36,398 & \\
5 & $30 \mu \mathrm{g} / \mathrm{mL}$ & 35,767 & 2.227 \\
& $40 \mu \mathrm{g} / \mathrm{mL}$ & 37,300 & \\
& $50 \mu \mathrm{g} / \mathrm{mL}$ & 37,240 & \\
\hline
\end{tabular}

Hasil uji pada formula krim menunjukkan terjadinya penurunan aktivitas antioksidan ekstrak ganggang hijau maupun lidah buaya setelah dikembangkan menjadi bentuk sediaan krim, hal ini diduga karena pada ekstrak tidak terdapat bahan kimia lainnya hanya mengandung senyawa aktif murni dari simplisia sedangkan sediaan krim terdapat bahan tambahan kimia lainnya sebagai basis krim sehingga ekstrak yang diformulasikan dalam bentuk sediaan krim memiliki aktivitas antioksidan yang lebih rendah ${ }^{13}$. Hal ini disebabkan karena telah bercampur dengan bahan kimia lainnya dengan demikian senyawa antioksidan dalam ekstrak ganggang hijau maupun lidah buaya akan berkurang dalam menstabilkan raikal bebas yang ada dalam basis krim.

\section{KESIMPULAN DAN SARAN}

Berdasarkan hasil penelitian dapat disimpulkan bahwa sediaan krim kombinasi antara ekstrak ganggang hijau (Ulva lactuca L.) dan lidah buaya (Aloe vera) yang paling baik berdasarkan uji mutu fisiknya yaitu formula 3 dengan kandungan zat aktif ekstrak ganggang hijau dan lidah buaya masing-masing sebanyak 1,5 g dan 0,5 g. Jika ditinjau dari kktivitas antioksidan, formula 3 pada krim kombinasi antara ganggang hijau dan lidah buaya yang paling baik secara fisik dengan nilai $\mathrm{IC}_{50}$ sebesar $304,411 \mu \mathrm{g} / \mathrm{mL}$.

Hasil evaluasi dari hasil penelitian ini untuk penelitian kedepannya perlu ditingkatkan konsentrasi zat aktif pada formula sediaan krim karena dalam hal memformulasi suatu sediaan topikal perlu dilakukan peningkatan konsentrasi atau dosis zat aktif sebanyak 2-3 kali karena sediaan topikal harus dapat menembuas membran agar dapat diabsorbsi dan menimbulkan efek maka dari itu diperlukan konsentrasi zat aktif yang cukup pada sediaan topikal tersebut. 


\section{KONFLIK KEPENTINGAN}

Seluruh penulis menyatakan tidak terdapat potensi konflik kepentingan dengan penelitian dan atau publikasi artikel ini.

\section{DAFTAR PUSTAKA}

1. Mahmud I, Pertiwi R, Azis NR, Reviana DN. Pemanfaatan Potensi Ganggang Hijau (Ulva Lactuca) Sebagai Antioksidan Alami Pada Pencegahan Infark Miokard Akut. 2014;1-7.

2. Gülçin I. Comparison of in vitro antioxidant and antiradical activities of L-tyrosine and L-Dopa. Amino Acids. 2007;32(3):431-8.

3. Wasri dan Any Guntary. Aktivitas Antioksidan Ekstrak Metanol Paprika Kuning (Capsicum annuum,L) dengan Metode Penangkapan Radikal DPPH. 2017;7:123-32.

4. Tamat SR, Wikanta T, Maulina LS. Aktivitas Antioksidan dan Toksisitas Senyawa Bioaktif dari Ekstrak Rumput Laut Hijau Ulva reticulata Forsskal. J IImu Kefarmasian Indones. 2007;5(1):31-6.

5. Julyasih KSM, Wirawan IG., Harijani WS, Widajati W. Aktivitas Antioksidan Beberapa Jenis Rumput Laut (Seaweeds) Komersial Di Bali K. Semin Nas "Akselerasi Pengemb Teknol Pertan dalam Mendukung Revital Pertanian." 2009;1-10.

6. Emelda and Annisa F. Antioxidant Activity of Ethanolic Extract of Green Algae (Ulva lactuca Linn.) From Sepanjang Beach Gunung Kidul with DPPH Method. First Asia-Pasific Partnersh Heal Nutr Improv Concerence. :76.

7. Septiawan AN. No Title. Akt Antioksidan Komb Ekstrak Etanol Lidah Buaya (Aloe vera L) dan Ganggang Hijau (Ulva Lact L). 2020;

8. Furnamawanthi I. khasiat dan manfat lidah buaya: si tanaman ajaib. jakarta; 2007. 4-29 p.

9. Khaing TA. Evaluation of the antifungal and antioxidant activities of the leaf extract of aloe vera (Aloe barbadensis Miller). World Acad Sci Eng Technol. 2011;51(3):609-11.

10. Alakh SN, D DS. Formulation \& Evaluation of Curcuminoid Based Herbal Face Cream. Indo-Global J Pharm Sci. 2011;1(1):77-84.

11. Wibowo SA, Budiman A, Dwi H. Formulasi Dan Aktivitas Anti Jamur Sediaan Krim M/A Ekstrak Etanol Buah Takokak (Solanum Torvum Swartz) Terhadap Candida Albicans. J Ris Sains dan Teknol. 2017;1(1):22-36.

12. Rachmalia N et al. Daya Iritasi dan Sifat Fisik Sediaan Salep Minyak Atsiri Bunga Cengkih (Syzigium aromaticum) pada Basis Hidrokarbon. Maj Farm 12372-376. 2016;

13. Zulkarya LG dan Erna DH. No Title. Formulasi Sediaan Krim Ekatrak Etanol Rumput Laut Coklat (Padina Aust dan Uji Akt Antioksidan Menggunakan DPPH. 2018;Vol 2 No 1.

14. Harun DSN. Formulasi dan Uji Aktivitas Antioksidan Krim Anti- Aging Ekstrak Etanol 50\% Kulit Buah Manggis (Garcinia magostana L.) dengan Metode DPPH ( 1,1 - Diphenyl-2Picril Hydrazil). 2014. 16 p.

15. Zainab dan Choirunisa Amalia Hanifitri. No Title. Akt Antioksidan Fraksi Etil Asetat Dari Ekstrak Etanol 50\% Daun Murbei Hitam (Morus nigra L) Dengan Metod DPPH Serta Penetapan Kadar Fenol Total. (Universitas Ahmad Dahlan).

16. Tw SP, Bachtiar A, Firmansyah D. Uji Aktivitas Antioksidan Krim Kombinasi Ekstrak Daun Jambu Biji (Psidium guajava L .) Dan Ekstrak Umbi Wortel (Daucus carota L .) Dengan Menggunakan Metode DPPH ( 2 , 2-diphenyl-1- picrylhydrazyl ). J Med Sains. 2018;3(1):31-42. 